1 Jenne JW, Siever JR, Druz WS, Solano JV, Cohen SM, Sharp JT. The effect of maintenance theophylline therapy on lung work in severe chronic obstructive pulmonary disease while standing and walking. Am Rev Respir Dis 1984;130: $600-5$

2 Chrystyn H, Mulley BA, Peake MD. Dose response relation to oral theophylline in severe chronic obstructive airways disease. $B M \mathcal{F}$ 1988;297:1506-10.

3 Noseda A, Schmerber J, Prigogine T, Yernault JC. Perceived effect of shortness of breath of an acute inhalation of saline or terbutaline: variability and sensitivity of a visual analogue variability and sensitivity of a visual analogue scale in patients with asth
Respir $\mathcal{F} 1992 ; 5: 1043-53$.

4 Noseda A, Schmerber J, Prigogine T, Yernault JC. How do patients with asthma or COPD perceive an acute bronchodilation? Eur Respir f 1993;6:636-44

5 Yernault JC. Rationale and assessment of acute drug trials in asthma. Eur Respir Rev 1991;1: 51-6.

\section{Bioavailability of salbutamol}

We read with interest the paper of Hindle and Chrystyn (May 1994;49:549-53) in which the lung bioavailability of salbutamol (Ventolin, Allen \& Hanburys, Uxbridge, UK) was augmented by $53.4 \%$ by using a Nebuhaler (Astra Pharmaceuticals, Kings Langley, UK) as assessed by 30 minute urinary excretion of salbutamol in normal volunteers. In this respect, measuring the plasma concentration of salbutamol, peak levels occur within five minutes of inhalation, in keeping with rapid lung absorption, and it is this which will therefore largely determine systemic $\beta_{2}$-mediated effects of inhaled salbutamol. ${ }^{12}$ That lung bioavailability determines systemic effects is supported by two studies. ${ }^{34}$ Firstly, salbutamol given by inhalation but not by mouth spraying produces a tachycardia and, secondly, mouth washing does not attenuate the systemic effects of inhaled salbutamol.

On the basis of the data of Hindle $e t$ al one might predict that the use of the Nebuhaler should increase the systemic $\beta_{2}$ effects of salbutamol in comparison with a metered dose inhaler. This was not found to be the case, however, in the study where systemic $\beta_{2}$ responses to cumulative doubling doses of salbutamol $(100-2000 \mu \mathrm{g})$ were compared in normal subjects using a metered dose inhaler and Nebuhaler as no differences were seen between the systemic dose-response curves. ${ }^{5}$ Although it may not be possible to extrapolate between the two studies, the inference is that measurements of 30 minute urinary salbutamol excretion may not be a true reflection of lung bioavailability,which may be directly measured using peak plasma concentration. Indeed, this is supported by a study where the increased plasma salbutamol concentration with a modified actuator device compared with a metered dose inhaler was associated with a left shift in the dose-response curve for a number of $\beta_{2}$-mediated systemic effects. ${ }^{2}$

There have been recent concerns regarding the bioequivalence of generic salbutamol metered dose formulations, particularly with regard to safety evaluation in terms of systemic $\beta_{2}$ effects. Thus, if it is required to quantify the systemic bioequivalence of generic inhaled salbutamol formulations, the use of direct pharmacokinetic evaluation of lung bioavailability using plasma salbutamol concentration along with measurement of systemic $\beta_{2}$ responses may be more appropriate than using an indirect surrogate pharmacokinetic parameter such as 30 minute urinary salbutamol excretion.

B J LIPWORTH A GROVE

Department of Pharmacology and Clinical Pharmacology, University of Dundee, Ninewells Hospital and Medical School,
Dundee DD1 $9 S Y$, Dundee DD1 9SY,

1 Newnham DM, Wheeldon NM, Lipworth BJ, McDevitt DG. Single dosing comparison of relative cardiac $\beta_{1} / \beta_{2}$ activity of inhaled fenoterol and salbutamol in normal subjects. Thorax 1993;48:656-8.

2 Newnham DM, McDevitt DG, Lipworth BJ. Comparison of the extrapulmonary $\beta_{2}$-adrenoceptor responses and pharmacokinetics of salbutamol given by standard metered dose inhaler and modified actuator device. $\mathrm{Br} f \mathrm{Clin}$ Pharmacol 1993;36:445-50.

3 Collier JG, Dobbs RJ, Williams I. Salbutamol aerosol causes a tachycardia due to the inhaled rather than the swallowed fraction. Br $\mathcal{f}$ Clin Pharmacol 1980;9:273-4.

4 Kung M, Croley SW, Phillips BA. Systemic cardiovascular and metabolic effects associated with the inhalation of an increased dose of with the inhalation of an increased dose of albuterol; influence of mouth

5 Lipworth BJ, McDevitt DG, Struthers AD. Systemic $\beta$-adrenoceptor responses to salbutamol given by metered dose inhaler alone and with pear shaped spacer attachment: comparison of electrocardiographic hypokalaemic and haemodynamic effects. $\mathrm{Br} \mathscr{f}$ Clin Pharmacol 1989;27:837-42.

AUTHOR'S REPLY The amount of salbutamol eliminated in the urine during the first 30 minutes after inhalation is an index of the dose delivered to the lungs, hence the term "relative bioavailability" to the lung. ${ }^{1}$ It is useful for the comparison of two inhaled products or methods when used by a patient. Furthermore, the method can differentiate between the fractions of dose delivered to the body by the pulmonary and oral routes. This is also true for plasma salbutamol concentrations, ${ }^{2}$ when measured after the inhalation of a first dose rather than following cumulative dosing. Peak plasma concentrations five minutes after inhalation, ${ }^{2}$ together with the polar and basic properties of salbutamol, are consistent with the large renal excretion we have reported in the first 30 minutes after an inhalation. ${ }^{1}$ Measurement of plasma salbutamol concentrations and the urinary excretion method do not indicate regional deposition in the lung and, therefore, are both indirect techniques.

The finding of greater deposition to the lung when a Nebuhaler was used with a metered dose inhaler (MDI) by Hindle $e t a l^{3}$ is consistent with that reported by others. ${ }^{45}$ During our study ${ }^{3}$ we did not measure systemic effects of salbutamol but subjects did report that tremor, between 5 and 20 minutes after inhalation, was greater when spacers were used. Lipworth and Grove cannot find an explanation for the greater lung deposition with spacers ${ }^{3-5}$ because a previous report has shown that extrapulmonary $\beta_{2}$ adrenoceptor responses were the same when an MDI was used with and without a spacer. ${ }^{6}$ This may be due to the specially prepared MDIs delivering 100 and $500 \mu \mathrm{g}$ per actuation used in their studies which could have affected the in vivo respirable fractions with and without the Nebuhaler. Furthermore, a cumulative dosing schedule was used and the systemic effects could be influenced by the total delivery of salbutamol to the body from the modified MDIs via pulmonary and oral routes. Lipworth et at do refer to this in their conclusion by stating that "improved lung delivery with a pearshaped spacer (PSS) may have compensated for reduced oropharyngeal deposition and gut absorption". Hence, without a measurement of the amount of salbutamol delivered to the body no comparison can be made between the study of Lipworth et at and those which demonstrate greater lung depositions with the Nebuhaler. ${ }^{3-5}$

Finally, we sympathise with the concerns of Lipworth and Grove with respect to the bioequivalence of inhaled products. We have shown that, using the same MDI, a variation in the technique significantly alters the amount of drug delivered to the lungs ${ }^{7}$ and that an efficient technique cannot be detected by subjective methods. ${ }^{8}$ If this occurred during a clinical study, especially the four period, two sequence randomised crossover design proposed by the FDA, then the issue of bioequivalence could be misrepresented. The need to carry out some simultaneous measure of lung deposition is highlighted by the confusion of Lipworth and Grove. Direct methods of measuring lung deposition require a modification to the aerosol and thus cannot be used in bioequivalence studies. Although the plasma salbutamol concentration measurements and the urinary excretion method are indirect methods, they do provide an indication of the relative in vivo respirable fractions delivered to the patient.

\section{H CHRYSTYN Professor of Pharmacy Practice, Bradford BD7 IDP, UK}

1 Hindle $M$, Chrystyn $H$. Determination of the relative bioavailability of salbutamol to the lung following inhalation. Brf Clin Pharmacol 1992; 34:311-5.

2 Newnham DM, McDevitt DG, Lipworth BJ. Comparison of the extrapulmonary $\beta_{2}$ adrenoceptor responses and pharmacokinetics of salbutamol given by standard metered dose inhaler and modified actuator device. Br f Clin Pharmacol 1993;36:445-50.

3 Hindle M, Chrystyn $H$. Relative bioavailability of salbutamol to the lung following inhalation using metered dose inhalation methods and spacer devices. Thorax 1994;49:549-53.

4 Vidgren MT, Paronen TP, Karkkainen A, Karjalianen P. Effect of extension devices on the drug deposition from inhalation aerosols. Int f Pharm 1987;39:107-12.

5 Newman SP, Miller AB, Lennard-Jones TR, Moren F, Clarke SW. Improvement of pressurised aerosol deposition with a Nebuhaler
spacer device. Thorax 1984;39:935-41.

6 Lipworth BJ, McDevitt D, Struthers AD. Systemic $\beta$-adrenoceptor responses to salbutamol given by a metered dose inhaler alone and with pear-shaped spacer attachment: comparison pear-shaped spacer attachment: comparison
of electrocardiographic hypokalaemic and of electrocardiographic hypokalaemic and haemodynamic effec

7 Hindle $M$, Newton PAG, Chrystyn H. Investigations of an optimal inhaler technique using urinary salbutamol as a measure of relative bioavailability to the lung. Thorax 1993; 48:506-11.

8 Hindle M, Chrystyn H. Metered dose inhalers. Pharm F 1991;246:722. 